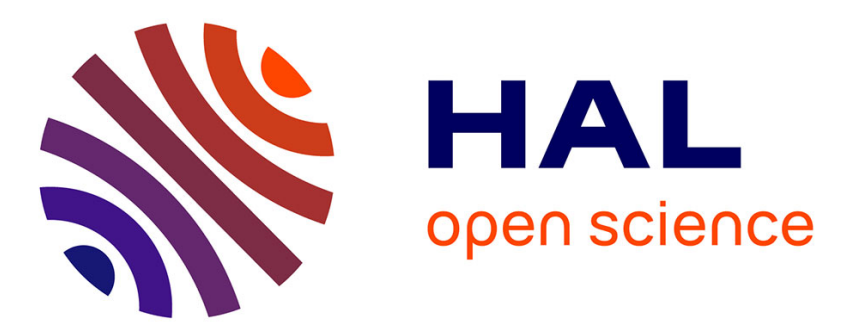

\title{
Magnetostrictive blocked-force clamping mechanism for secure and heavy-load inchworm motion
}

\author{
Bintang Yang, Guang Meng,, Pengyou Xu, Xiantao Tan, Zhi-Qiang Feng, \\ Dehua Yang,
}

\section{To cite this version:}

Bintang Yang, Guang Meng,, Pengyou Xu,, Xiantao Tan, Zhi-Qiang Feng, et al.. Magnetostrictive blocked-force clamping mechanism for secure and heavy-load inchworm motion. 2009 ASME Conference on Smart Materials, Adaptive Structures and Intelligent Systems (SMASIS2009), Sep 2009, Oxnard, CA, United States. pp.231-236, 10.1115/SMASIS2009-1268 . hal-01178646

\author{
HAL Id: hal-01178646 \\ https://hal.science/hal-01178646
}

Submitted on 13 Jan 2019

HAL is a multi-disciplinary open access archive for the deposit and dissemination of scientific research documents, whether they are published or not. The documents may come from teaching and research institutions in France or abroad, or from public or private research centers.
L'archive ouverte pluridisciplinaire HAL, est destinée au dépôt et à la diffusion de documents scientifiques de niveau recherche, publiés ou non, émanant des établissements d'enseignement et de recherche français ou étrangers, des laboratoires publics ou privés. 


\title{
MAGNETOSTRICTIVE BLOCKED-FORCE CLAMPING MECHANISM FOR SECURE AND HEAVY-LOAD INCHWORM MOTION
}

\author{
$\begin{array}{lll}\text { B.T. Yang, G. Meng, P.Y. Xu, X.T. Tan } & \text { X. }\end{array}$ \\ The state key lab of mechanical system and vibration, Jiao Tong University, Shanghai, China \\ Z.Q. Feng \\ Laboratoire de Mécanique, Université d'evry - Val D'essonne, 91020 Evry Cedex, France \\ D.H. Yang \\ Institute of Astronomical Optics \& Technology, Chinese Academy of Sciences, Nanjing, China
}

\section{ABSTRACT}

The capability of inchworm motor for long-displacement, heavy-load and precise positioning is greatly conditioned by the effectiveness of the clamping mechanism. A need exists in the art for clamping mechanism capable of delivering precise and heavy load motion. This paper presents a novel giant magnetostriction material (GMM) application to the development of such mechanism. GMM is advantageous over other smart materials in this particular aspect by its remarkable magnetostriction and especially the huge blocked stress. It can, e.g., display around $4000 \mathrm{~N}$ at moderate magnetization with a $\phi 25 \times 100 \mathrm{~mm}$ GMM rod. Most desirably, such large force could be used as clamping force in inchworm movement. However, the force can only be generated under blocked state, which is generally hard to reach, especially in a moving regime.

Addressing this problem, the research utilizes GMM rod's capacity to both positively stretch and negatively contract under permanent-magnet-biased condition and presents a specially designed clamping mechanism, a permanent-magnetbiased actuator fastened in a rigid guideway. Being applied reverse magnetic field, the formerly stretched actuator may contract to a suitable size to be put into the rigid guideway. Then, removal of the field will theoretically result in the restoration of the actuator. Practically, stretching of the actuator is blocked by the rigid guideway. This forms the so-called Preblocked-clamping-on state, where no-power fastening behavior exists. Moreover, the blocked force is adjustable. When being applied the same-direction field as the permanent one, the blocked force becomes greater (Blocked-clamping-on state). When being applied adequate reverse field, the blocked force is diminished with the shrinking of the actuator, till the actuator released from the rails (Blocked-clamping-off state). This process realizes the utilization of blocked force in clamping action, thus provides resolution for secure and heavy load inchworm motion. A clamping mechanism prototype (Size: $\phi 32 \times 130 \mathrm{~mm}$, with a $\phi 10 \times 100 \mathrm{~mm}$ GMM rod) has been realized. The design and working process of the setup is presented. Through experiments, the prototype can be facilely manipulated by square-instant and sinusoid-continuing current and it can agilely perform to meet the proposed blocked force the proposed clamping principle.

\section{INTRODUCTION}

Research into smart-material actuator rather than linear motor has long been the major focus, such as the work in precise positioning over micron-level span, in active vibration control, etc.. Precisely delivering and accumulating the superhigh precise deformation of solid-state smart material is a critical research task to challenge the usual belief that smart materials displacement is too small to adapt in long stroke driving application. The feasibility of applying inchworm moving principle to build a linear motor by steps accumulation to generate an infinite distance has attracted those who aim to change the small span driving actuator into a precise long distance driving motor. Combined with the development of smart materials and the inchworm moving principle, different prototypes of liner motors have been developed in the last decade. Amongst them, the capacity of motor on either large output force or precision positioning or both have been attempted to achieve by some novel and outstanding driving technologies[1-4]. Though researchers have recognized the importance of the clamping mechanism in implementing quality inchworm movement, they have so far emphasized more on its linear driving part and the solution to the inherent problems such as hysteresis[5], Joule heat[6], etc.. In fact, we have realized that without an adequate clamping mechanism it is not possible to achieve a smart-material inchworm motor with high precise positioning even if the above-mentioned 
problems were well resolved. The clamping mechanism more directly affects the motor both on the positioning precision and on the thrust capacity.

\section{CLAMPING MECHANISM OF LINEAR INCHWORM MOTOR}

A typical structure of a linear inchworm motor can be illustrated as an H-shaped structure, as shown in Fig.1. The motor is most necessarily constructed by Part A and $\mathrm{C}$ (the Clamping mechanism), Part B (the driving mechanism for doing displacement), and Part D (the guide-way). The motor can move as Part $\mathrm{A}, \mathrm{B}$ and $\mathrm{C}$ are excited in sequence and alternately to do clamping-on or clamping-off actions by $\mathrm{A}$ and $C$ against $D$, and stretching-on or stretching-off by $B$, see [4] for the detailed description.

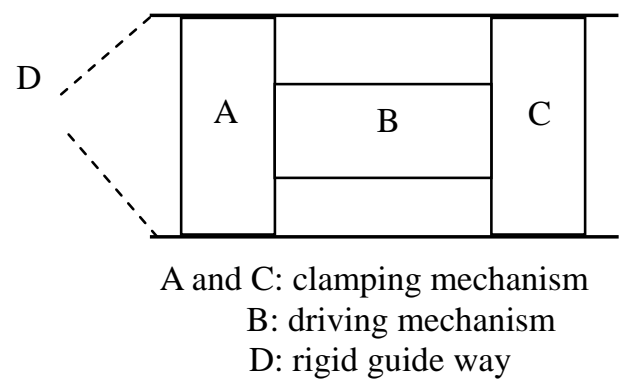

Fig. 1. Schematic of a typical inch-worm linear motor

Clamping mechanism $\mathrm{A}$ and $\mathrm{C}$ are placed into the guideway $\mathrm{D}$ to generate deformation for clamping in the vertical direction, while the driving part $\mathrm{B}$ is configured to produce displacement in the horizontal direction. The rigid guide-way D is used for both guiding the moving to be linear and providing clamping force (friction) as it squeezes the top and bottom ends of $\mathrm{A}$ or $\mathrm{C}$.

According to [5, 7], giant magnetostrictive material (GMM) has almost all the properties that are required for a clamping application, as listed in Table 1.

Table 1. GMM Properties in clamping application potentials

\begin{tabular}{lll}
\hline \multicolumn{1}{c}{ Properties } & Parameters & \multicolumn{1}{c}{$\begin{array}{c}\text { Potentials for } \\
\text { clamping } \\
\text { application }\end{array}$} \\
\hline $\begin{array}{l}\text { Giant and solid-state } \\
\text { magnetostriction }\end{array}$ & $\begin{array}{l}\text { Large and high- } \\
(\mathrm{ppm})\end{array}$ & $\begin{array}{l}\text { Land for } \\
\text { precision } \\
\text { deformation } \\
\text { clamping action } \\
\text { Remarkable }\end{array}$ \\
$\begin{array}{l}\text { compressive strength } \\
\text { Instant response } \\
\text { time }\end{array}$ & $<1 \mu 0(\mathrm{MPa})$ & $\begin{array}{l}\text { Attaining } \\
\text { remarkable press } \\
\text { Wideband clamping } \\
\text { frequency and no } \\
\text { clamping delay }\end{array}$ \\
\hline
\end{tabular}

\begin{tabular}{|c|c|c|}
\hline \multirow{3}{*}{$\begin{array}{l}\text { Efficient energy } \\
\text { transduction }\end{array}$} & $\begin{array}{l}0.7 \sim 0.75 \\
\text { (Coupling } \\
\text { factor) }\end{array}$ & \multirow{3}{*}{$\begin{array}{l}\text { Efficient energy } \\
\text { transduction from } \\
\text { electromagnetic to } \\
\text { mechanical, } \\
\text { facile clamping } \\
\text { control, adjustable } \\
\text { clamping force; }\end{array}$} \\
\hline & $\begin{array}{l}14 \sim 25 \\
(\text { Energy density } \\
\left.\mathrm{kJ} / \mathrm{m}^{3}\right)\end{array}$ & \\
\hline & $\begin{array}{l}49 \sim 56 \\
\text { Conversion } \\
\text { efficiency }(\%)\end{array}$ & \\
\hline $\begin{array}{l}\text { Available pre-biased } \\
\text { magnetostriction }\end{array}$ & $\begin{array}{l}500 \sim 1000 \\
\text { (ppm, } \\
\text { practically } \\
\text { available) }\end{array}$ & $\begin{array}{l}\text { Both extension and } \\
\text { contraction } \\
\text { clamping action } \\
\text { available by DC or } \\
\text { Permanent magnet } \\
\text { biasing }\end{array}$ \\
\hline
\end{tabular}

Some competent clamping technologies for inchworm movement, including the ones using smart materials, have been developed and reported in the literature. Kim et al [8] present a self-moving cell mechanism that can execute both driving and clamping actions during an inchworm movement. Park et al [9] report another clamping method that is rather unique, in which for generating large clamping force, micro-ridges fabricated through MEMS technology is used. There are respective advantages in both clamping mechanisms. The Cell-clamping mechanism can produce large clamping force by the ring elastic deformation against the walls of a guide-way which makes the cell move without slippage and with linearly guided movement. The Microridge-clamping mechanism can also produce large clamping force due to the enhanced friction by the meshed micro-ridges, which also makes the system move with high step-moving repeatability.

Nevertheless, we realize that there is still room for improvement on the clamping mechanism. Some limitations mainly related to the above two clamping mechanism types exist in such aspects as that: the cell-clamping one's maximum clamping force is most likely limited by the initial configuration, and the clamping force is unable to adjust any larger during work, and the Microridge-clamping one's step is confined by the size of the microridge, the larger the microridge is, the less the resolution becomes.

Aiming to improve the current smart-material clamping technology, a novel giant magnetostrictive clamping mechanism has been proposed in this paper. This clamping mechanism can on the one hand render remarkable and adjustable clamping force as a result of fully demonstrating the GMM property in high stress, on the other hand realize a preclamping regime enabling a no-power clamping ability that is necessarily important for fastening the mechanism body when needed to work at certain slantwise position and on the poweroff occasion. 


\section{THE PRINCIPLE OF THE NEW MAGNETOSTRICTIVE CLAMPING MECHANISM}

Magnetostriction can be described generally as deformation of body in response to a change in its magnetization and characterized by an even function of the magnetic field [7], which implies that magnetostriction is proportional to strength $\mathrm{H}$ of the applied magnetic fields, and the magnetostriction is independent of the sign of the applied longitudinal magnetization as well. In addition, another fundamental effect to realize the new magnetostrictive clamping principle is that a GMM rod can perform both expansion and contraction by magnetizing it in sequence with two magnetic fields, $\mathrm{H}_{1}$ and $\mathrm{H}_{2}$ as illustrated in Fig. 2, both having a magnetic field but with different strength and in opposite directions. This is basically how elongation and contraction are achieved with a GMM rod. Precisely thanks to this effect, the clamping-on or clamping-off actions are realized. Therefore, the principle of the new GMM clamping mechanism is established.

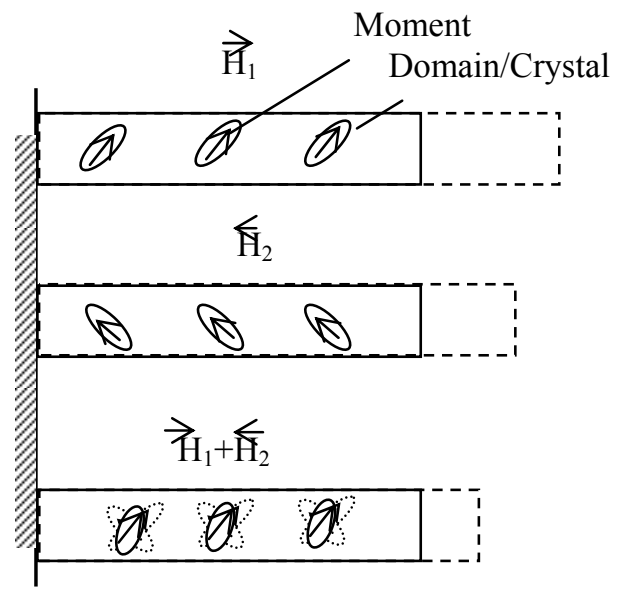

Fig. 2. Illustration to the magnetostrictive expansion and contraction

Accordingly, a clamping mechanism as shown in Fig. 3 has been realized. It is pre-biased by two permanent magnet barrels for field $\mathrm{H}_{1}$, and is excited by a solenoid for $\mathrm{H}_{2}$. Through controlling the exciting field $\mathrm{H}_{2}$, an entire clamping process can be performed, which is illustrated in Fig. 4. $\mathrm{M}$ and $\mathrm{G}$ indicate the clamping mechanism and the rigid guide-way, respectively; and $\mathrm{M}$, for mimicking its motion when following an inchworm motor walk, is illustrated to go through $\mathrm{G}$ from the left side to the right side by such 6 procedures as: 1) $\mathrm{M}$ permanent-biased by the magnet barrels for an initial stretch, 2) contracting $\mathrm{M}$ by exciting opposite field to the permanent one, meanwhile $M$ cutting in $G, 3$ ) making $M$ be in pre-clamping or clamping-on state by cutting off the exciting field, since at this moment, within the rigid guide-way, $\mathrm{M}$ tends to recover its initial state and thereby be squeezed in the rigid guide-way (the guide-way width is lesser than the length of the clamping mechanism being stretched in initial state), 4) applying and adjusting the exciting field again, the squeezed extent for $\mathrm{M}$, i.e. the clamping force adjusted, 5) stopping adjustment, $M$ returning to the pre-clamping state, finally 6 ) contracting $M$ by applying the field opposite to the permanent field till the squeeze loosed, getting $\mathrm{M}$ out of $\mathrm{G}$, ceasing excitation, $\mathrm{M}$ going back to 1) the initial state. By far, an entire clamping process has been performed.

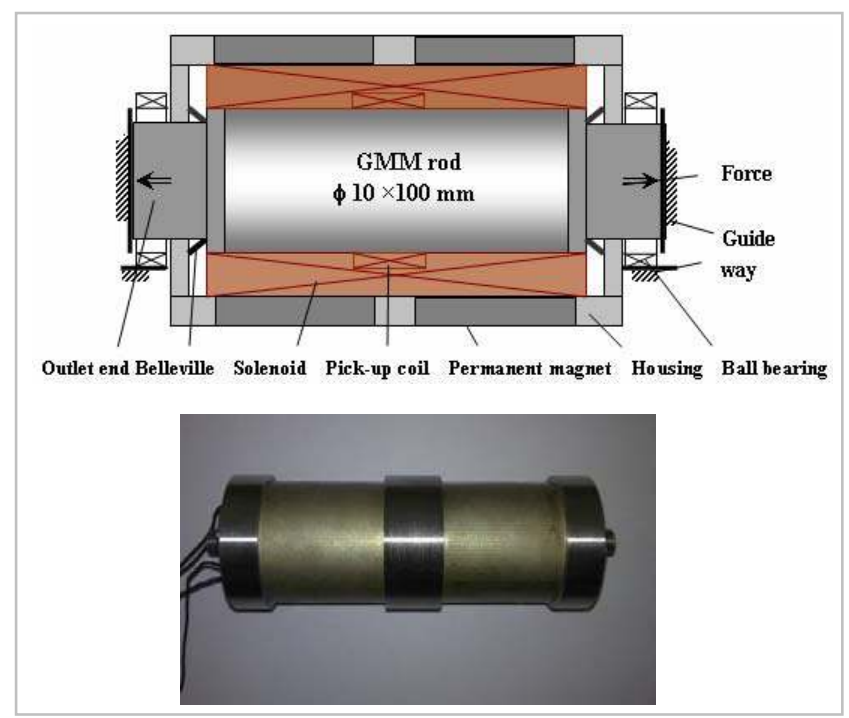

Fig. 3. The structure of the clamping mechanism and the prototype photo

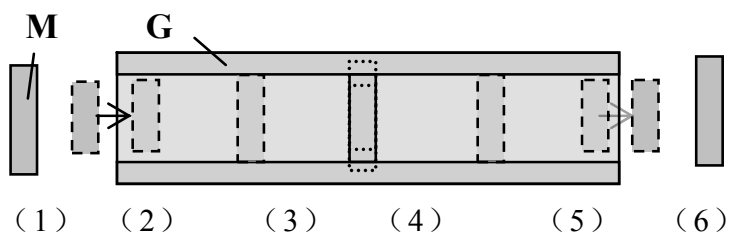

Fig. 4. Illustration to the principle of the magneto-elastic clamping mechanism

\section{EXPERIMENTAL VERIFICATION TO THE CLAMPING PRINCIPLE}

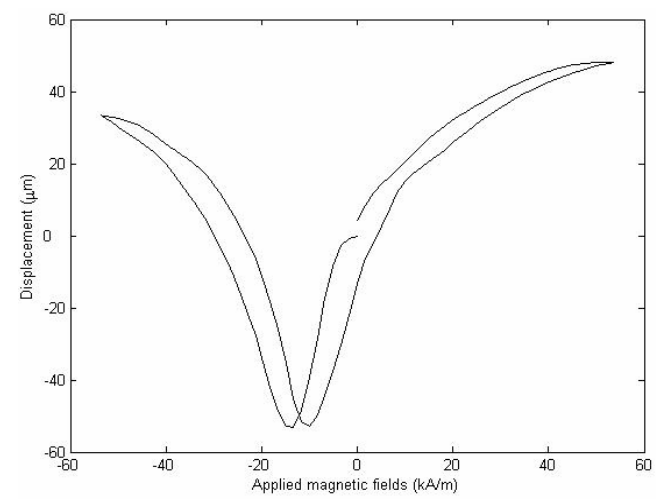

Fig. 5. The generated displacement of the prototype by applying scanning magnetic fields (scanning currents vary from $-8 \mathrm{~A}$ to $8 \mathrm{~A}$ ) 
Fig. 5 shows the experiment result for testing the expansion and contraction capacity of the prototype with a size of $\phi 32 \times 130 \mathrm{~mm}$, driven by a $\phi 10 \times 100 \mathrm{~mm}$ GMM rod. The prototype is excited with a 670 -turns and $1 \mathrm{~mm}$ thread diameter solenoid and pre-biased by two barrel permanent magnet (NdFeB). Meanwhile, there is a $7 \mathrm{MPa}$ prestress, which is settled according to our previous study[4], applied on the rod through Belleville springs. A Keyence LK-G30 Laser sensor is used to measure the net displacement.

Plot in Fig. 5 displays the prototype deformation varied with the scanning magnetic fields from -53.6 to $53.6 \mathrm{kA} / \mathrm{m}$. According to the result, the maximum contraction $-53 \mu \mathrm{m}$ under $-13.4 \mathrm{kA} / \mathrm{m}$ (-2A current) electromagnetic fields and the maximum stretch $48 \mu \mathrm{m}$ under $53.6 \mathrm{kA} / \mathrm{m}$ (8A current) fields, so that the total $101 \mu \mathrm{m}$ variable displacement, without any external load, were reached. This displacement capacity of the clamping mechanism is supposedly enough to meet the requirement for completing the proposed clamping principle. And we have further completed another experiment in order to verify each clamping action of the new clamping principle that is illustrated in Fig. 4. The experiment setup is shown in Fig. 6, in which a leading-screw pressing jig and a press sensor are employed. The sensor is sandwiched between the downsideend of the leading-screw and a rigid aluminum bar which is against the upside-end of the standing clamping-mechanism on an aluminum base. By this setup the clamping mechanism can be demonstrated to do the proposed clamping actions in a guide-way that is constructed by the aluminum bar and the aluminum base.

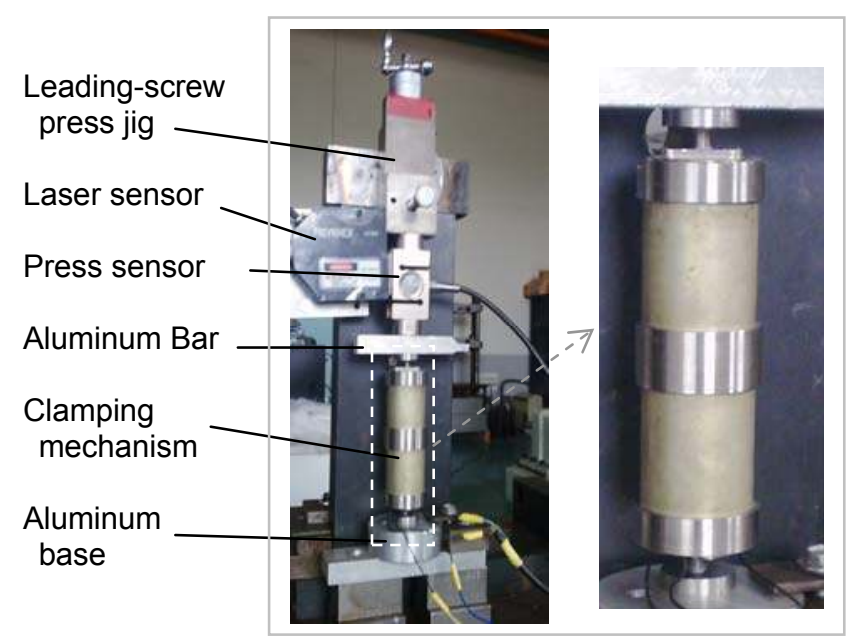

Fig. 6. Experiment setup for the test of the clamping principle
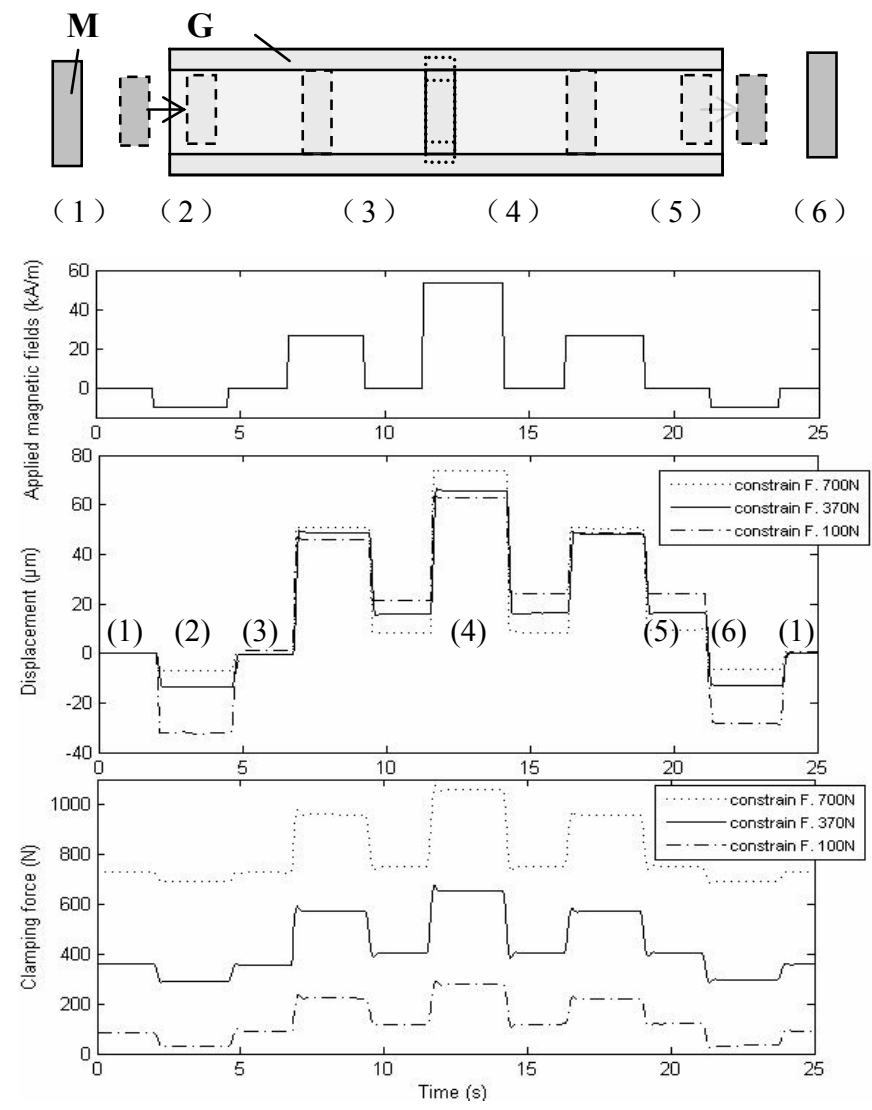

(a)

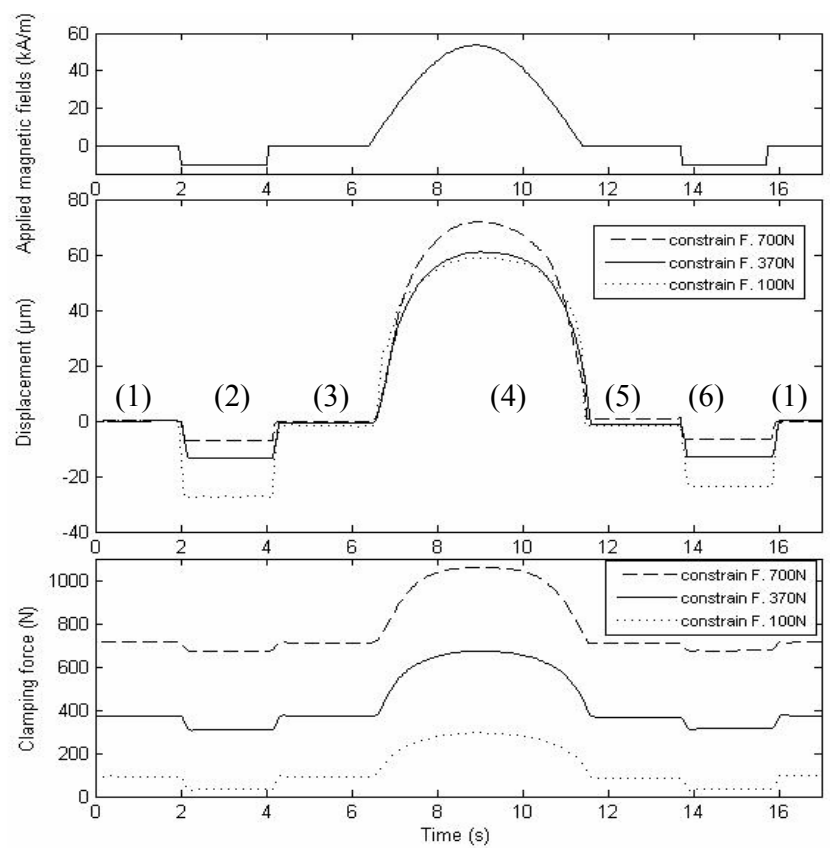

(b)

Fig. 7. The generated displacement and clamping force under different constrains by series exciting: (a) by series square currents exciting, (b) by series square and half-sine currents exciting 
In order to simulate the clamping process and demonstrate the related clamping functions, two structured series magnetic fields (i.e. two series currents) have been applied to the prototype, meanwhile both the clamping force and the clamping displacement have been measured through the displacing sensor and the press sensor. It should be noted that though the constructed guide-way by the current setup can offer convenience to measure the clamping change in distance, but can by no means keep completely rigid for measuring the real clamping force, because the employed strain-gauge presssensor itself can deliver withdrawing displacement, when against the clamping force. Nevertheless, we have artificially made the guide-way to be as rigid as possible by applying constraining presses up to $700 \mathrm{~N}$ through the leading-screw press jig. The test results are presented in Fig. 7, wherein the variation procedures in clamping displacement are numbered precisely according to the 6 procedures of an entire clamping process as those shown in Fig. 4.

Figure 4 is presented again together with Fig. 7 for the convenient reference. In Fig.7(a), the exciting fields are generated by a series of square currents only, while in Fig.7(b) the magnetic fields are generated by another series of currents that comprise square currents and a half-sine current. Moreover, during the test, different press: $100 \mathrm{~N}, 370 \mathrm{~N}$ and $700 \mathrm{~N}$ for constraining the guide-way was putting on, respectively.

The result, first of all, shows that the new clamping mechanism can be facilely manipulated by instant current (square current) or continuing current (half-sine current) signals and it can agilely perform every action to meet the proposed clamping principle satisfactorily. Secondly, it shows that the more constrain applied on the guide-way, the larger clamping force generated. To be specific, under the current test setup, maximum $1050 \mathrm{~N}$ (that is the measuring range of the employed press sensor) clamping force can be obtained when the displacement reaching maximum to around $73 \mu \mathrm{m}$ under $700 \mathrm{~N}$ constrain force, with the clamping adjusting procedure (4) being performed either by the square currents or by the half-sine current. Supposedly, the clamping force potential of this prototype may be distinctively improved if the guide-way provides complete rigidness, to reach up to $1800 \mathrm{~N}$ according to Kellogg in literature[10]. In addition to the improvement in clamping force, the pre-clamping force of the mechanism may also be greatly improved upon desirably rigid guide-way. With reference to Fig. 5, for the maximum negative displacement $53 \mu \mathrm{m}$, the clamping mechanism prototype may generate up to $626 \mathrm{~N}$ (according to Kellogg and calculated by the equation (3), young's modulus $15 \mathrm{GPa}$ at $6.9 \mathrm{MPa}$ [10]) pre-clamping force. This force is sufficient to hold the clamping mechanism tightly.

Finally, for another attempt to obtain the ideal blockedclamping force, a new setup, shown in Fig.8, has been further constructed. The new guideway comprises of two brass rails specially fastened by a hydropress bench-clamp. Supposedly, this new setup may avoid the degradation in clamping force due to the insufficient rigidity like that in the previous setup as shown in Fig.6.

This time the maximum clamping force is deduced indirectly by the thrust i.e. the friction between the ends of the clamping mechanism and the two rails of the guide-way.

On the one hand, the press-sensor, with its both ends pushed against the leading-screw jig (the same one as used in the previous setup) and the side of the clamping mechanism, has detected the thrust of up to $244 \mathrm{~N}$. On the other hand, the friction-factor between the brass rail and steel end of the blocked-clamping mechanism is selected with $0.08 \sim 0.1$, according to the handbook of mechanical design[11]. Thus, the maximum clamping force capacity of the designed clamping mechanism is able to reach $1220 \mathrm{~N} \sim 1525 \mathrm{~N}$.

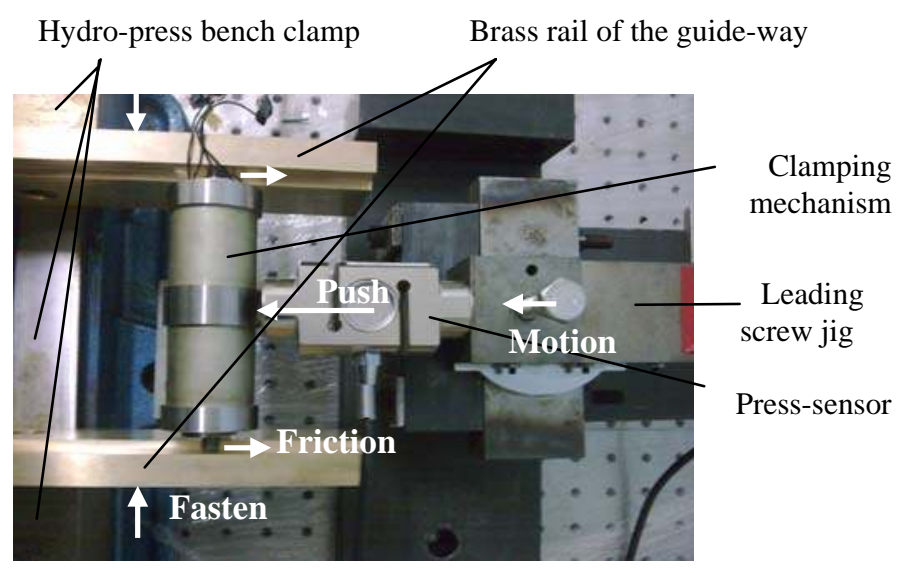

Fig. 8 A new setup for detecting the clamping force capacity

Unfortunately, the theoretically maximum $1800 \mathrm{~N}$, according to[10], has not yet be obtained even under this new setup, since expending displacements up to around $20 \mu \mathrm{m}$ of the brass guideway is yet detected as the clamping mechanism performs blocked-clamping actions. This result has stressed us that a mono-case guideway with very sufficient rigidity should be necessarily equipped in the coming motor research. It will take a most necessary role for demonstrating the mechanism's ideal clamping capacity, and the outstanding loading behaviour of the designed motor.

\section{CONCLUSIONS}

GMM has been well known especially for its capability of generating significant driving force with super-high energy density. In applications, this outstanding property, however, has not yet been adequately implemented. This paper has presented a new clamping principle that may contribute to inchworm-like linear motor executing great loading capacity, infinite long but very precise displacement, superior stable motion with no backlash and no tilt, and position holding by its peculiar nopower latching behaviour. This paper has verified that the novel clamping principle acts very well through a prototype 
completing each procedure of the proposed clamping process. The prototype with a size of $\phi 32 \times 130 \mathrm{~mm}$, driven by a $\phi 10 \times 100 \mathrm{~mm}$ GMM rod has been tested. The clamping force can be adjusted to reach up to $1050 \mathrm{~N}$. And the maximum clamping and pre-clamping force can achieve around $1800 \mathrm{~N}$ and $626 \mathrm{~N}$ respectively, when served a fully rigid guide-way. The pre-clamping force proves strong enough to hold the clamping mechanism, so the future motor based on this technology may remain its position firmly even on no-power supply occasion. A new constructed rigid brass guideway that is fastened by a hydropress bench clamp is further employed, for attempting to obtain the maximum clamping force of up to $1525 \mathrm{~N}$, which is near the theoretically maximum blocked clamping force, $1800 \mathrm{~N}$.

The prospective inchworm motor may travel with no backlash, no tilt, no inertia slip, and it may avoid dropping out of a sloped guideway as current cuts off. Such motor has potential to substitute precise leading-screw plants in accurate heavy-load transportation.

\section{ACKNOWLEDGMENTS}

The research is partially supported by NSFC (Grant No.10778620), Shanghai Pujiang Program (No. 08PJ1406100), the open project of state key lab MSV(2009-15), and SRF for ROCS, SEM. The authors are grateful to their great supports.

\section{REFERENCES}

[1] Joshi C. H., 2000, "Compact magnetostrictive actuators and linear motors", Proc. $7^{\text {th }}$ International Conference on New Actuators Bremen, Germany pp.120-125
[2] Kim J. W., Kim J. D. and Choi S. B., 2002, “A hybrid inchworm linear motor", Mechatronics 12 pp.525 - 542

[3] Cusin P., Sawai T. and Konishi S., 2000, "Compact and precise positioner based on the Inchworm principle", $J$. Micromech. Microeng. 10 pp.516-521;

[4] Yang B.T., Bonis M., Tao H., Prelle C. and Lamarque F., 2006, "Magnetostrictive mini actuator for long-stroke positioning with nanometer resolution", J. Micromech. Microeng. 16 pp. 1227-1232

[5] Calkins F. T., Smith R. C. and Flatau A. H., 2000, "An energy-based hysteresis model for magnetostrictive transducers", IEEE Trans. Magn.36 (2) pp. 429-439

[6] Yamamoto Y., Eda H. and Shimizu J., 1999, “Application of giant magnetostrictive materials to positioning actuators" Proc.IEEE/ASME of International Conference on Advanced Intelligent Mechatronics Atlanta, USA pp. $215-220$

[7] Engdahl G. 2000 Handbook of giant magnetostrictive materials (San Diego, CA: Academic Press)

[8] Kim J., Doo J. K., 2003, "Magnetostrictive self-moving cell linear motor" J. Mechatronics 13 pp. 739-53

[9] Park J., Mitrovic M., Carman G. P. and Hahn H.T., 2000, "Design and testing of a mesoscale actuator device (MAD)" Proc. SPIE, 3985 pp. 717-728

[10] Kellogg R., Flatau A., 2004, "Blocked-force Characteristics of Terfenol-D Transducers", J. of intelligent material systems and structures 15 pp. 117-128

[11] Handbook of mechanical design
[M], DigitalVersion,2008, Beijing: Chemical Industry Press (in Chinese) 